SUPPORTING INFORMATION (1)

\title{
FOR
}

\section{Silatropic Carbonyl Ene Cyclisations in the Synthesis of Pseudosugars and Hydroxylated Piperidines}

\author{
Jeremy Robertson,* Petra M. Stafford, Stephen J. Bell
}

Department of Chemistry, University of Oxford, Chemistry Research Laboratory, Mansfield Road, Oxford, OX1 3TA, UK

${ }^{13}$ C NMR SPECTRA FOR NEW COMPOUNDS:

(But-2-ynyl)diphenylsilane; Z-(but-2-enyl)diphenylsilane $\quad$ S2

7,8

9, (S)-Methyl $N$-(benzyloxycarbonyl)[(3-methylbut-2-enyl)di(iso-propyl)silanyloxy]isoserinate $\mathrm{S} 4$

$11,12,13$

15,16

18,20

S7

21, thiocarbonate leading to $\mathbf{2 2}$

$\mathbf{2 2}$, thiocarbonate leading to $\mathbf{2 3}$

$\mathbf{2 3}$, thiocarbonate leading to $\mathbf{2 4 ,} 24$ 

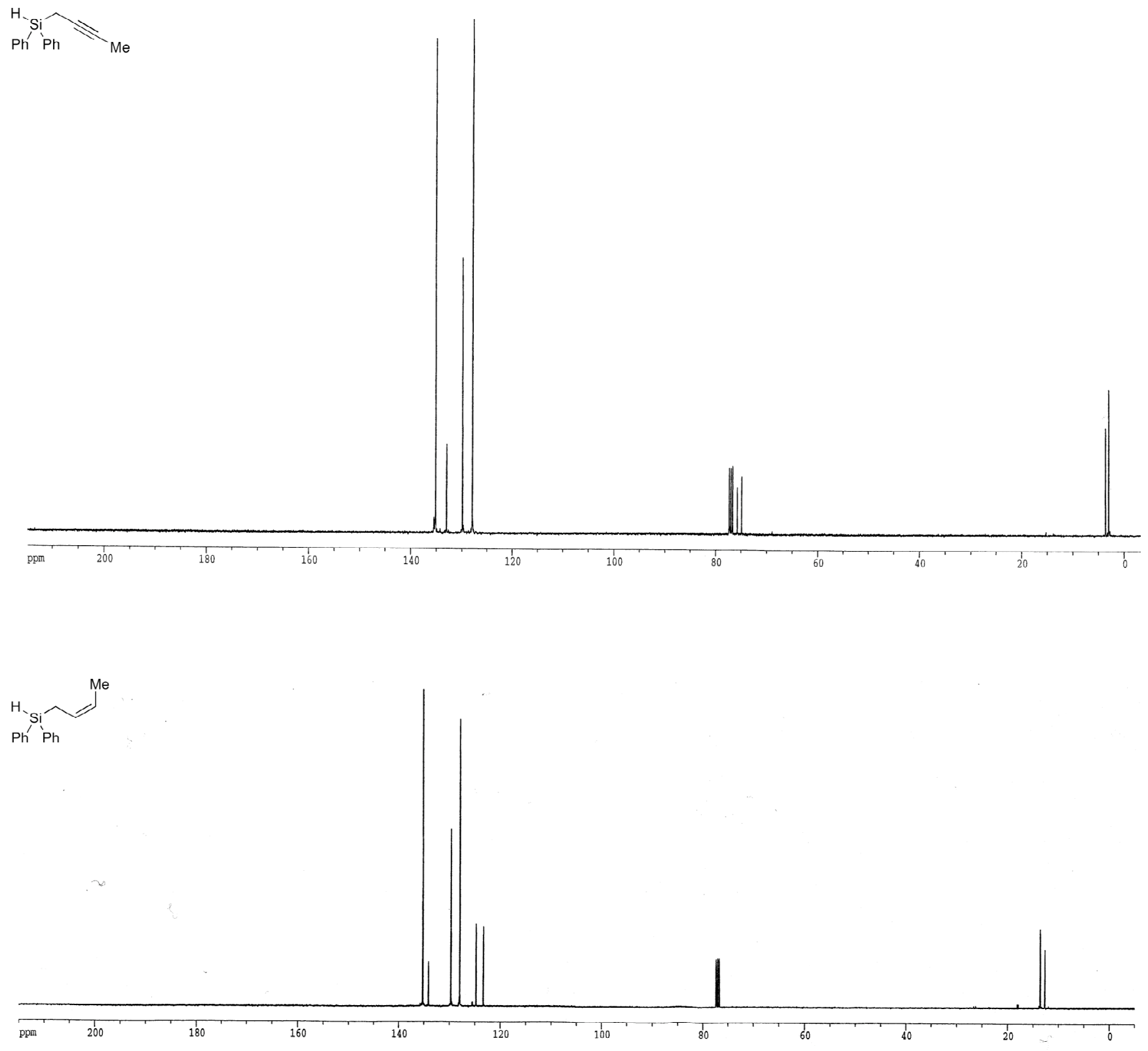

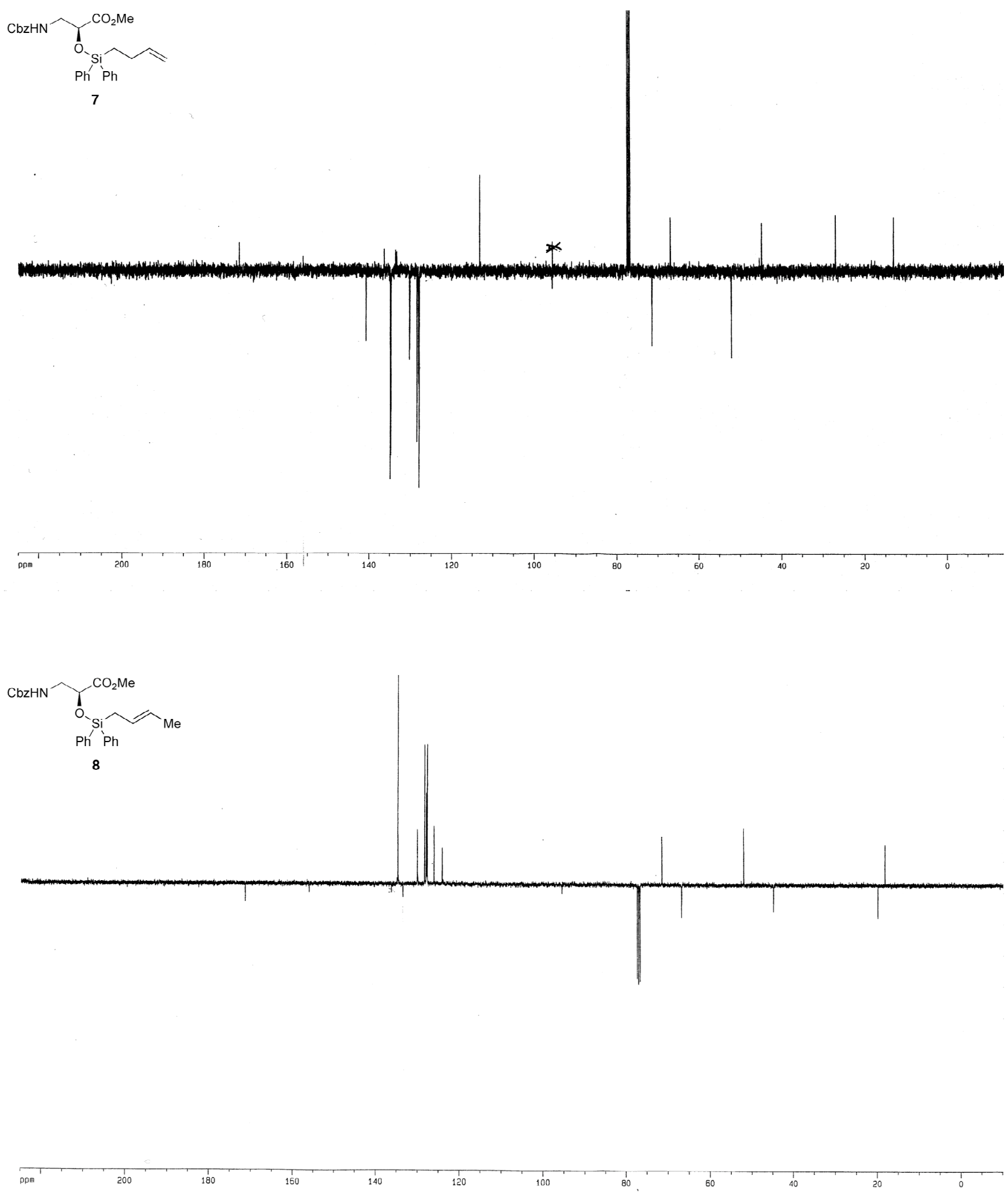


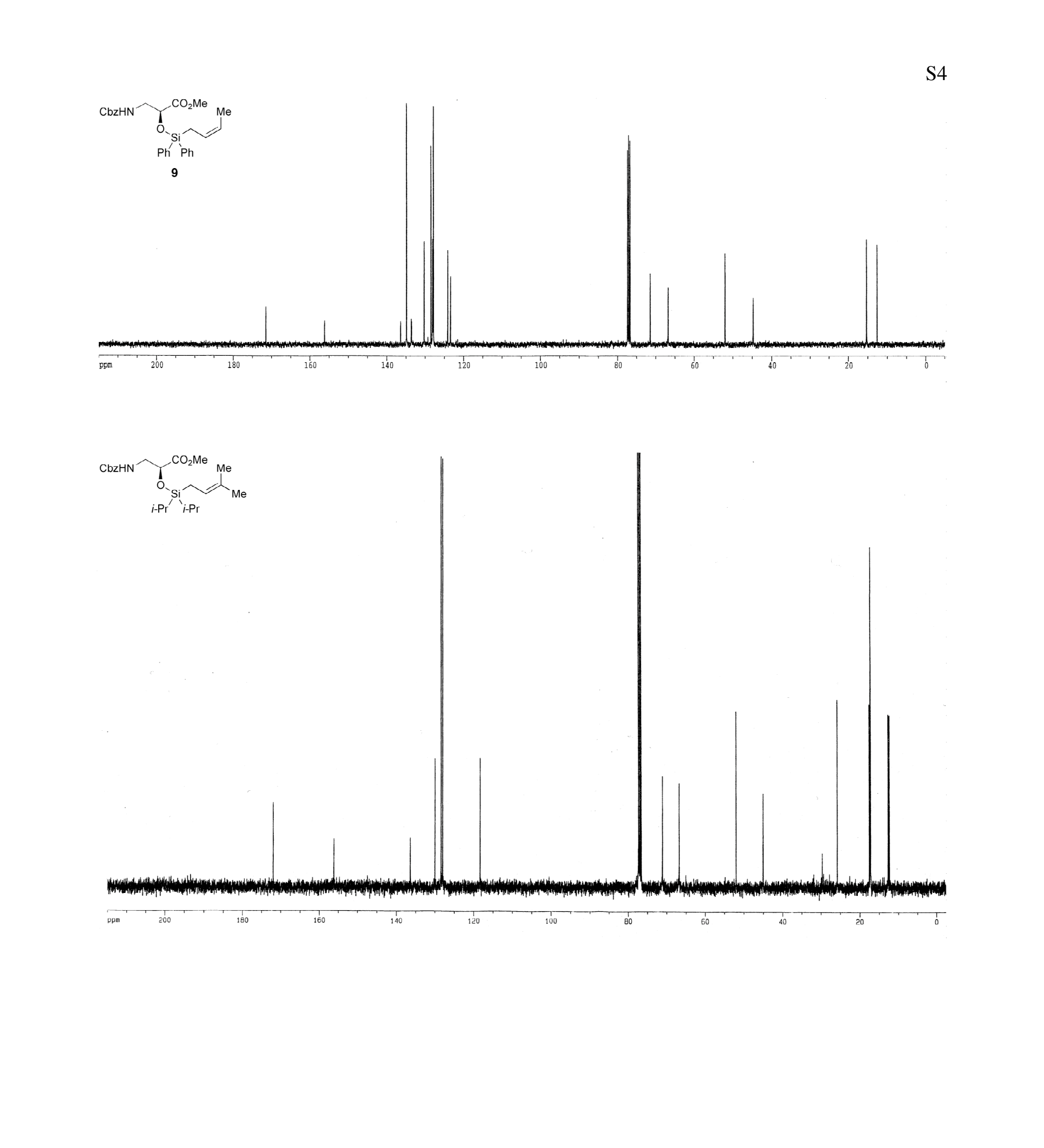


S5

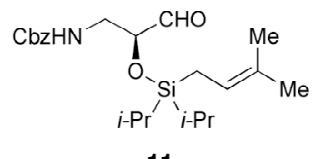

11

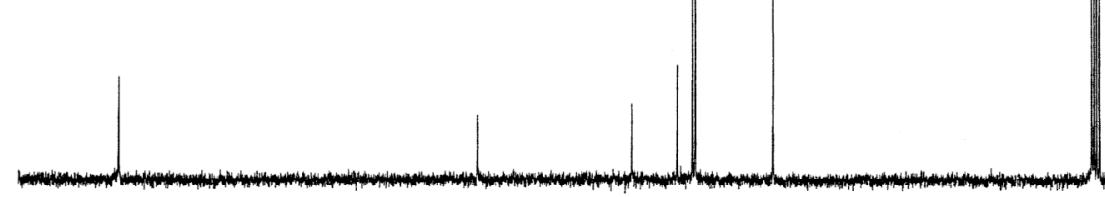

(pen

$\mathrm{Ph}^{\prime} \mathrm{Ph}$

12
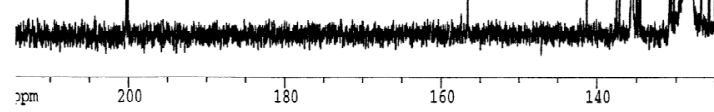
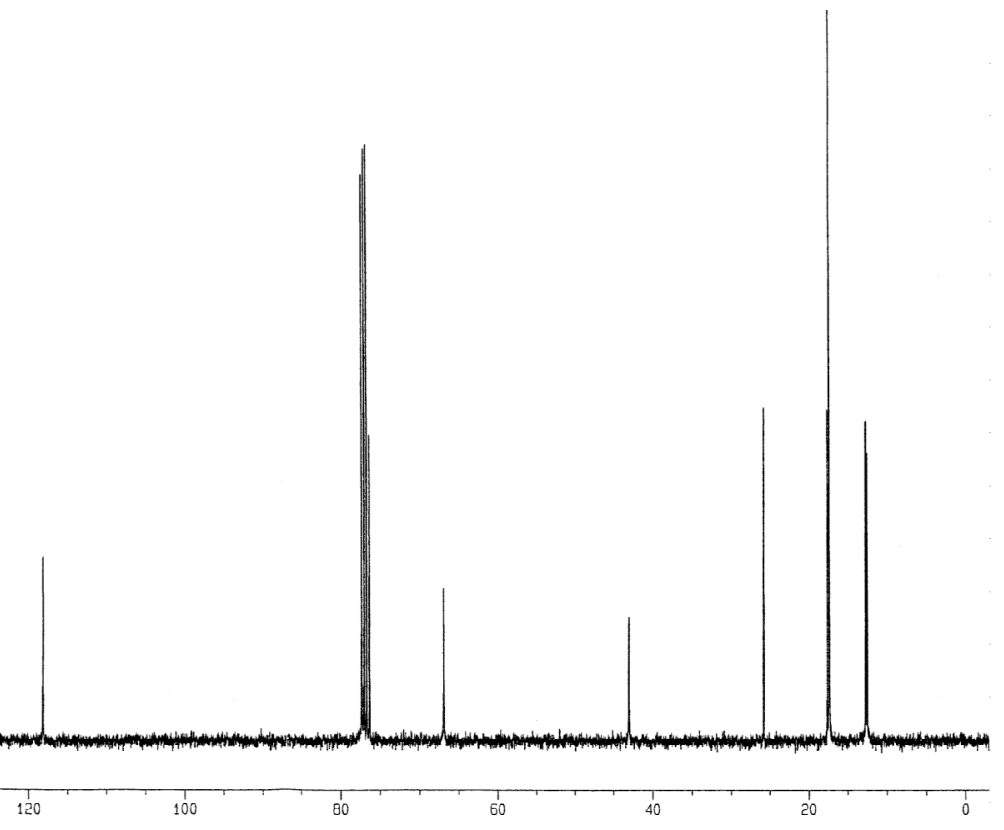

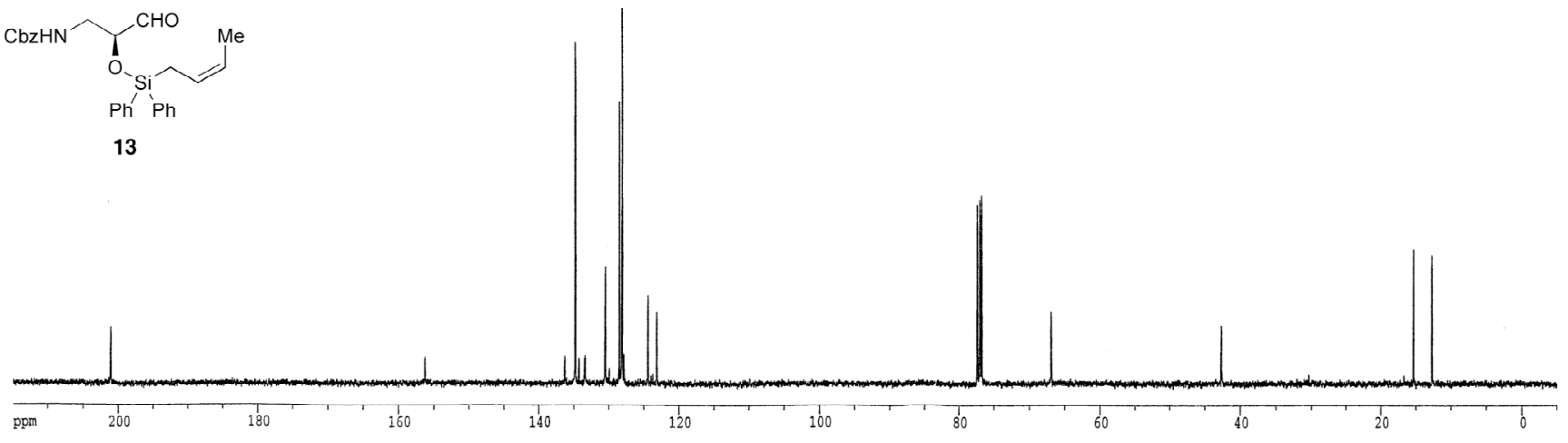


S6

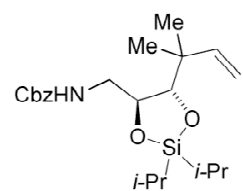

15

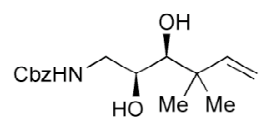

16

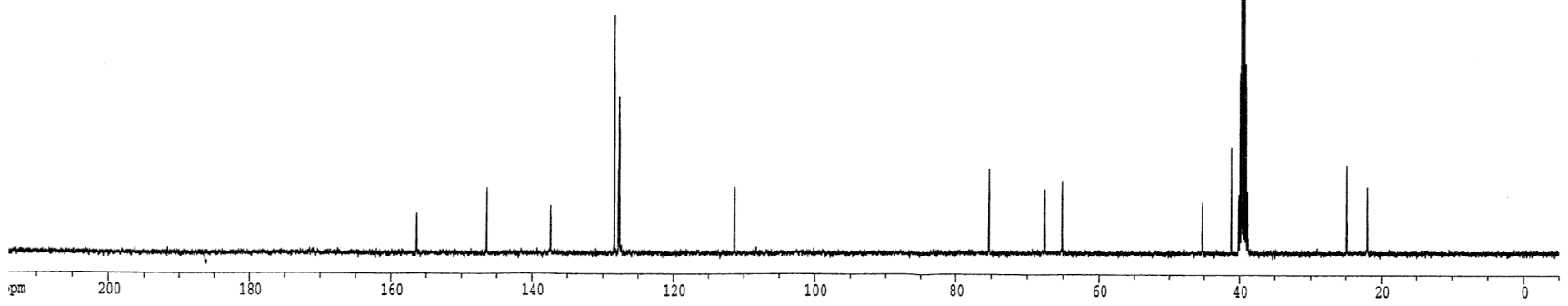




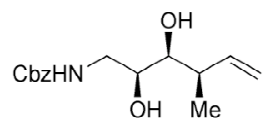

18
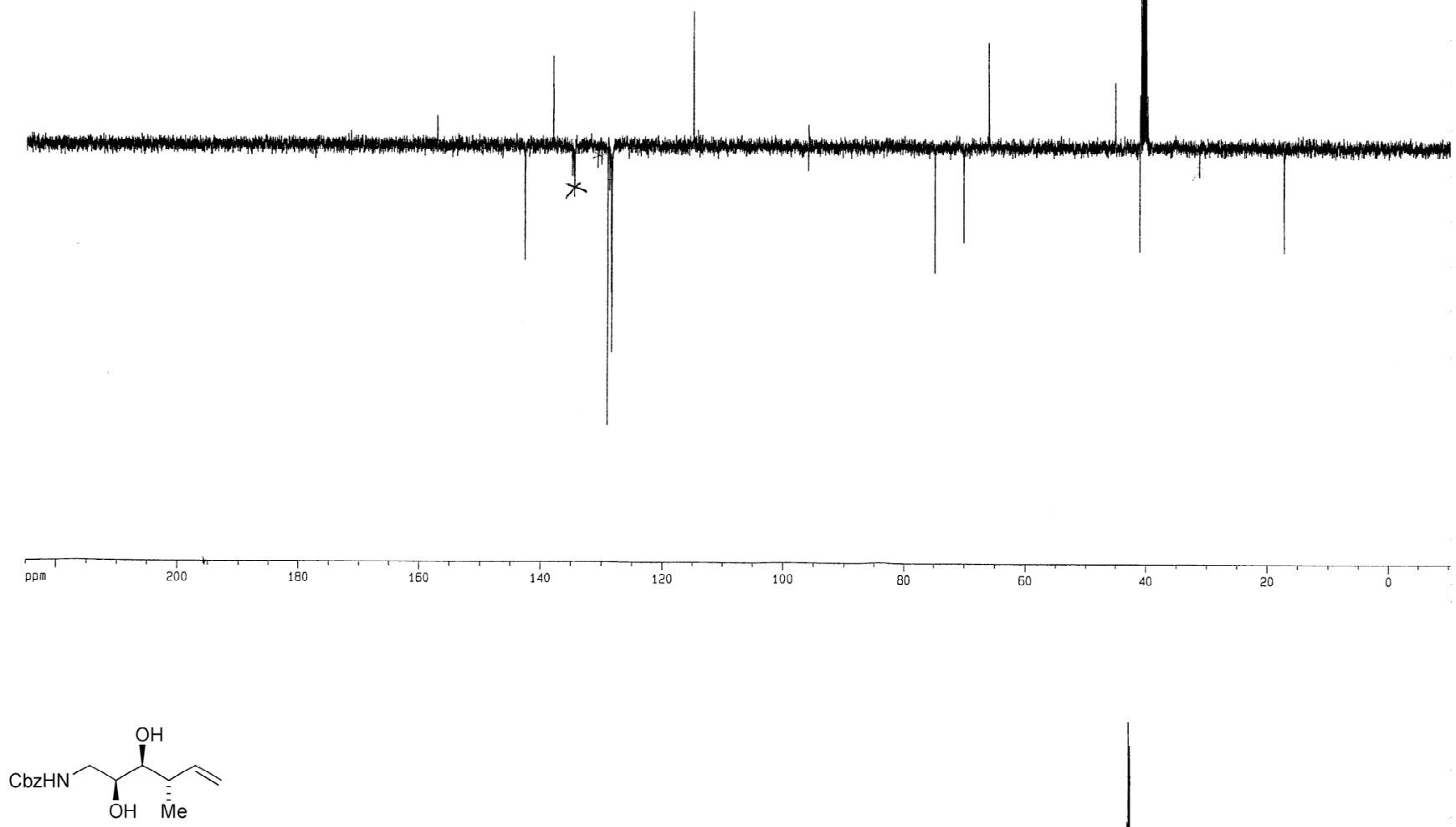

20
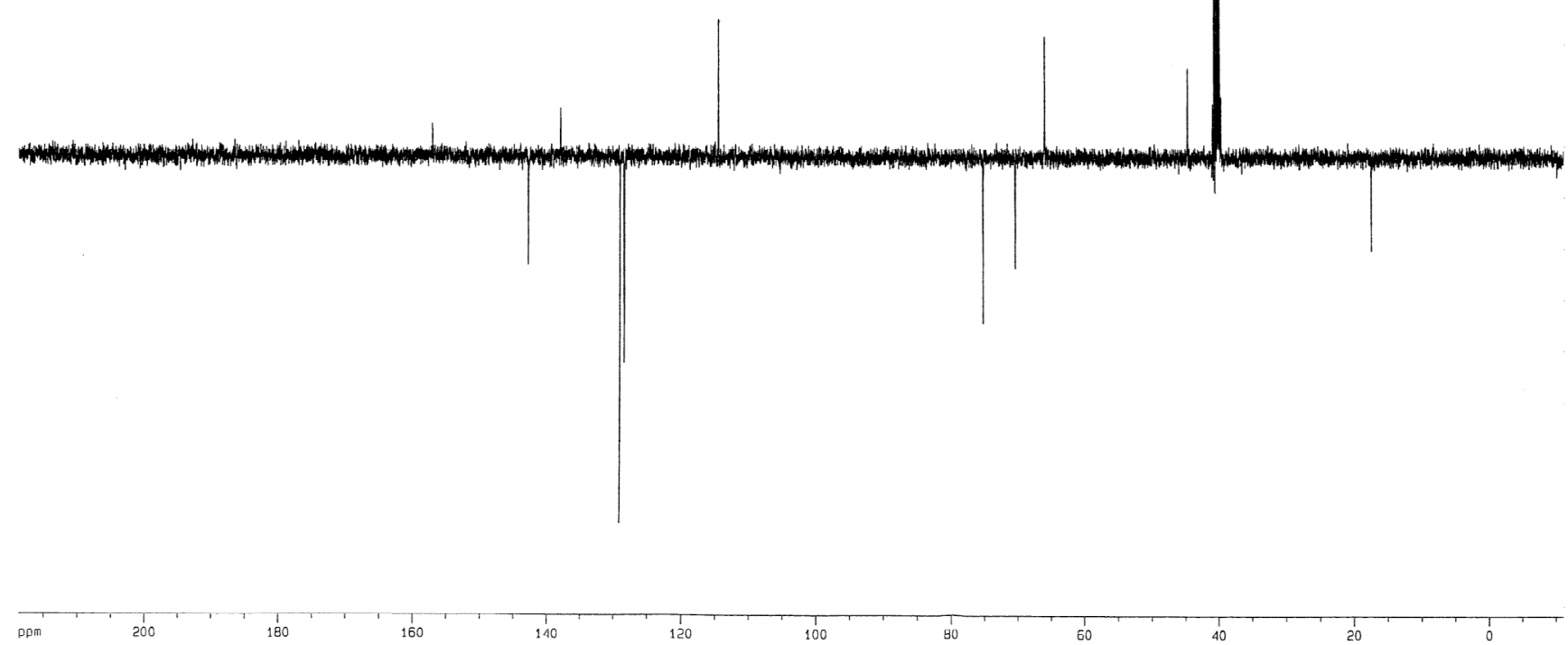
$\mathrm{CbzHN} \frown \overbrace{\mathrm{OH}}^{\mathrm{OH}} \curvearrowright$

21
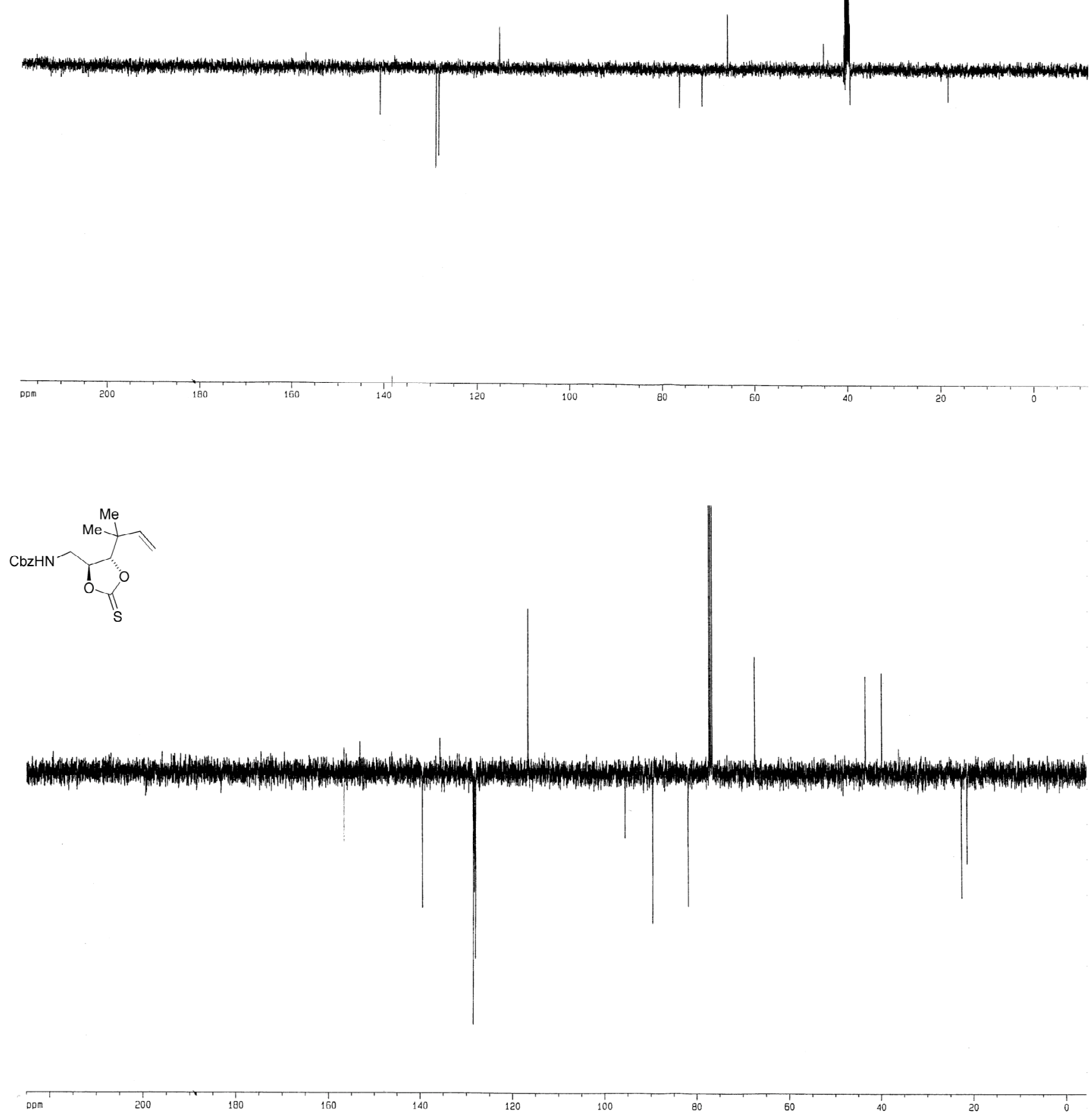
S9
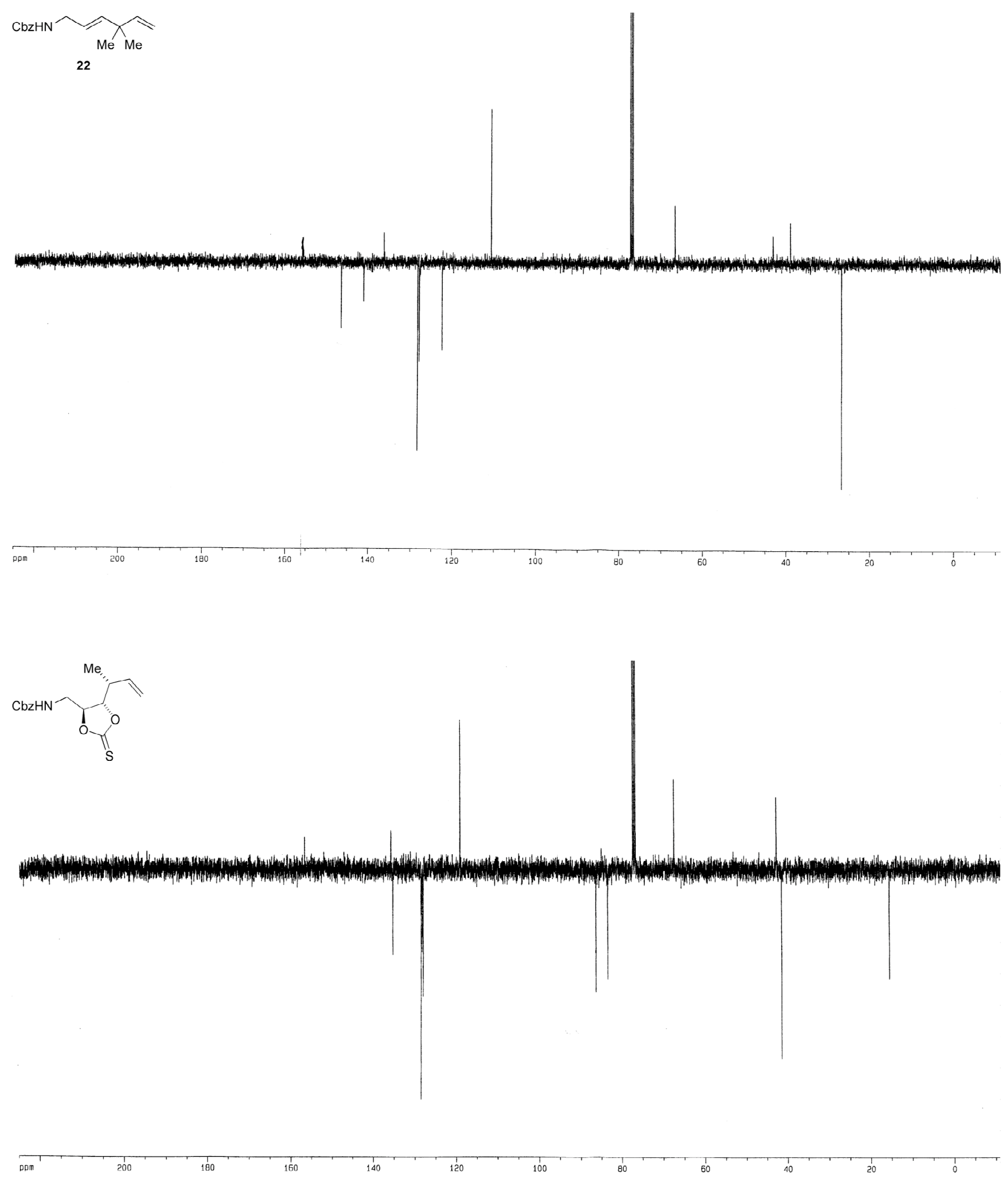

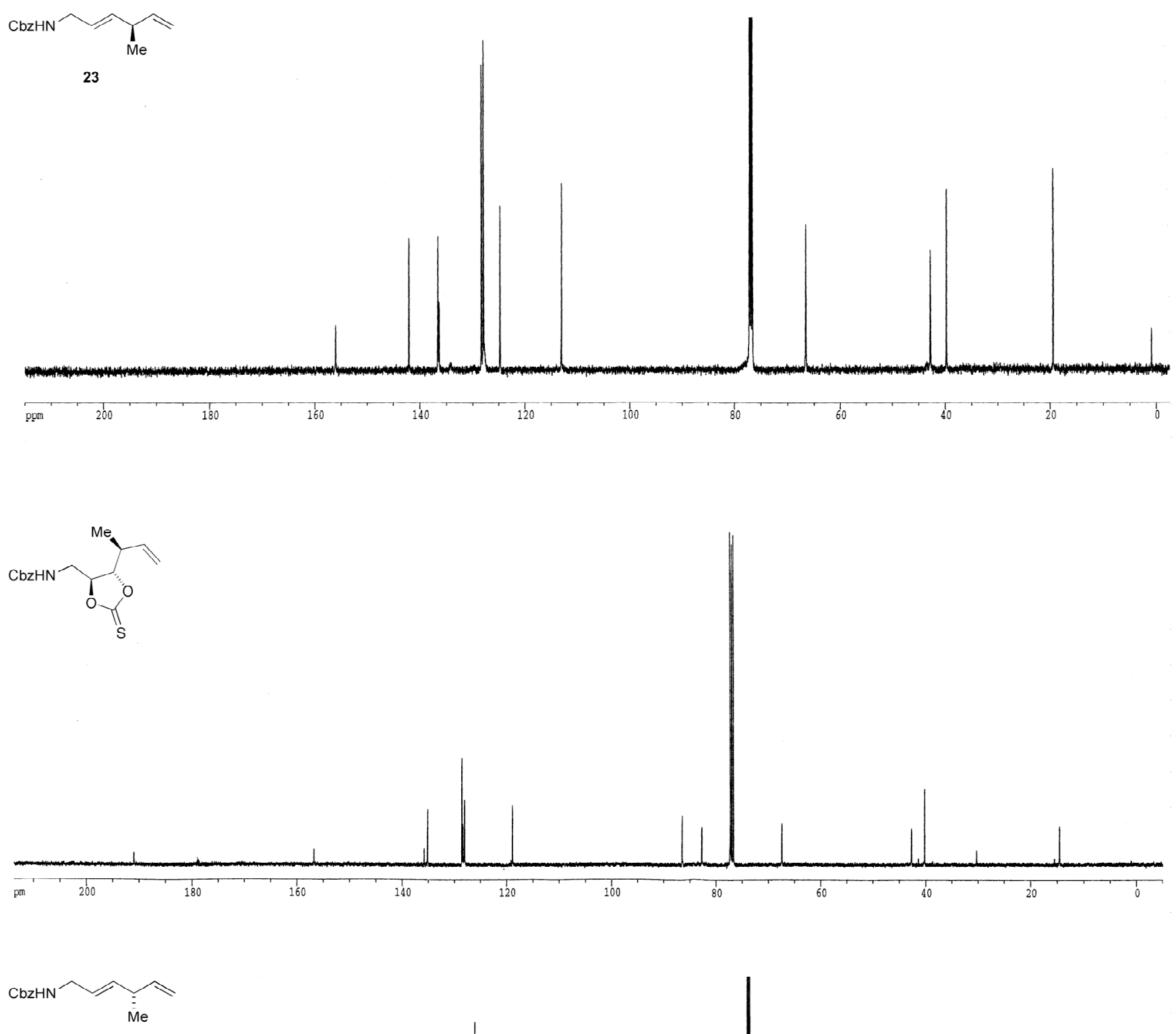

24

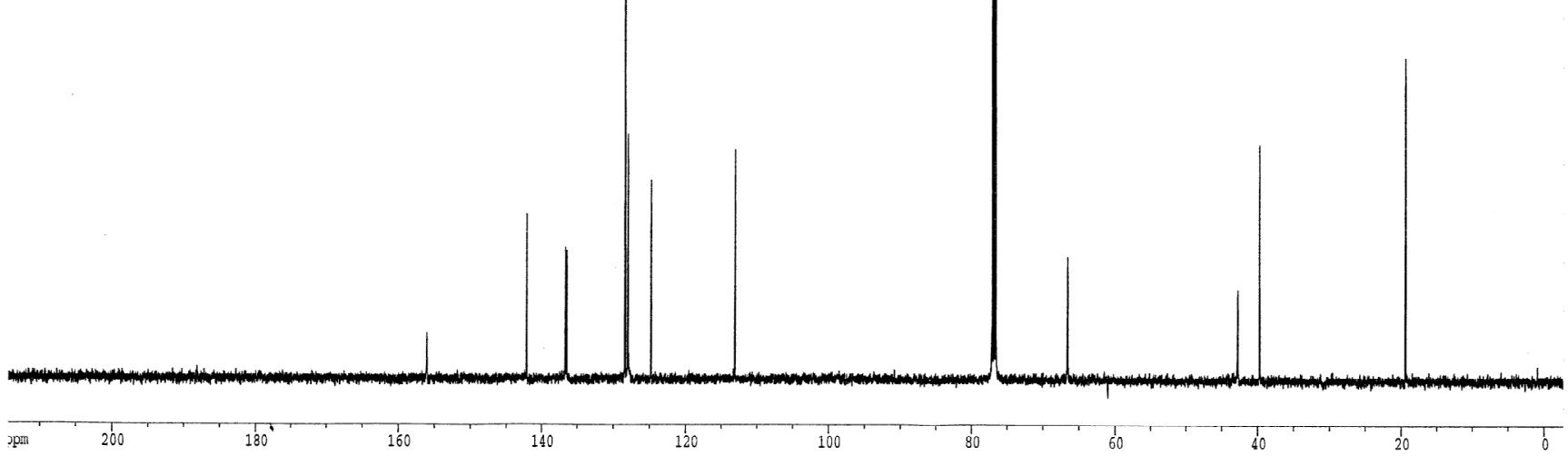


S11
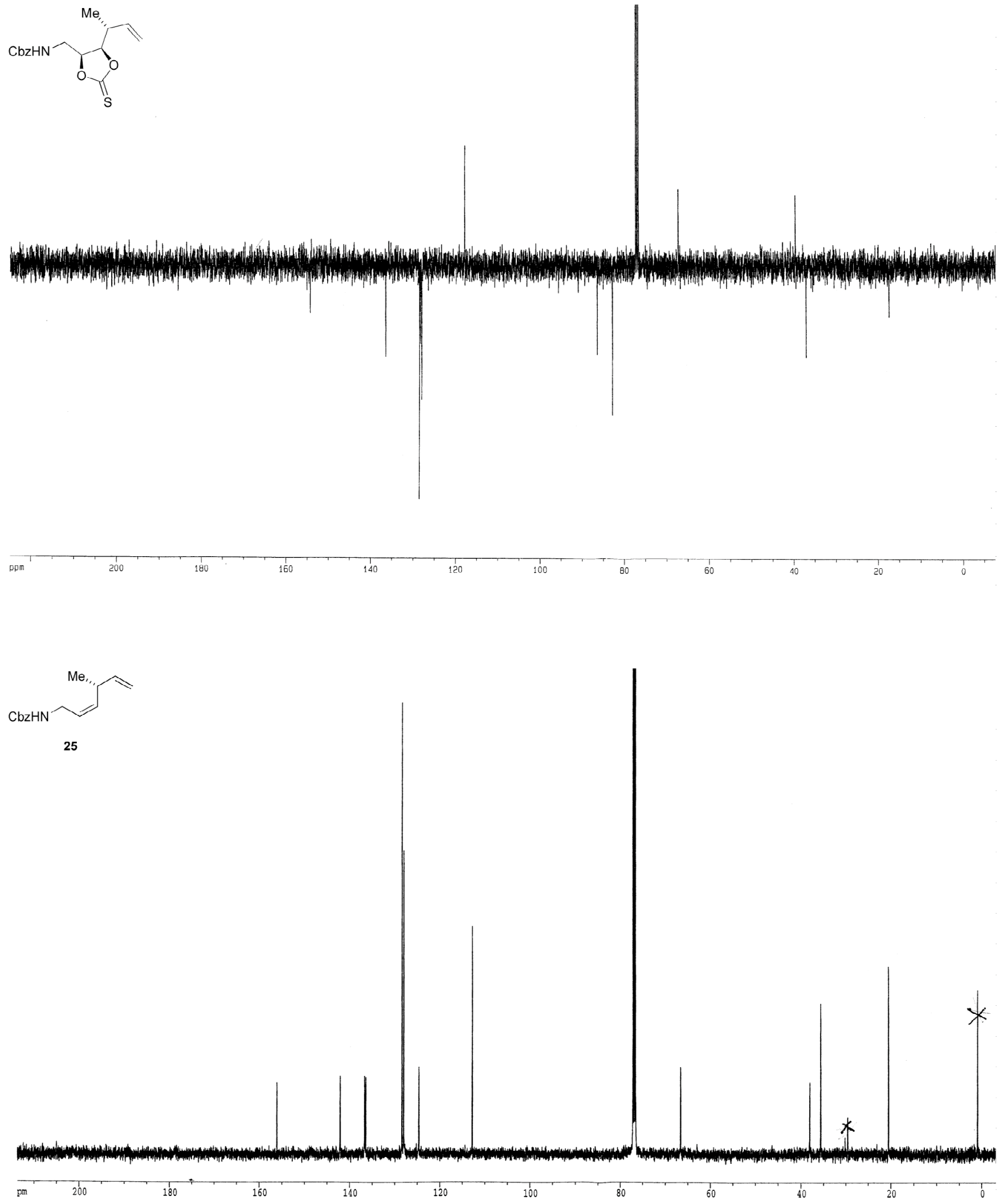
${ }_{\mathrm{AC}}^{\mathrm{OAC}}$

28
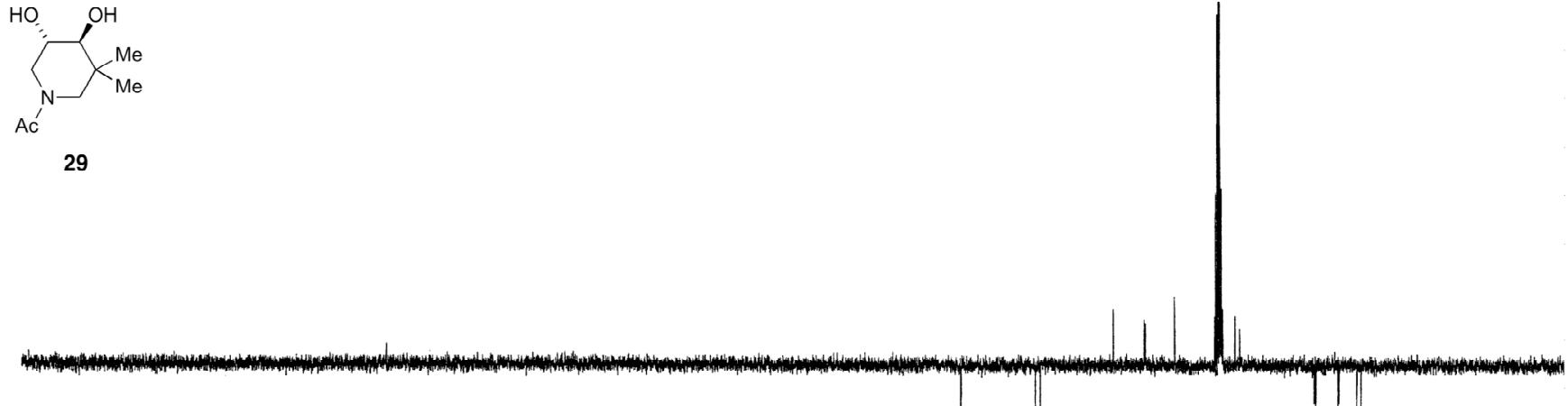

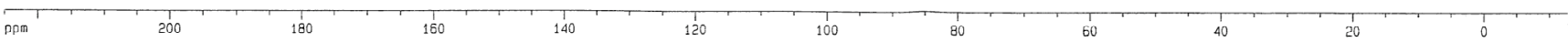



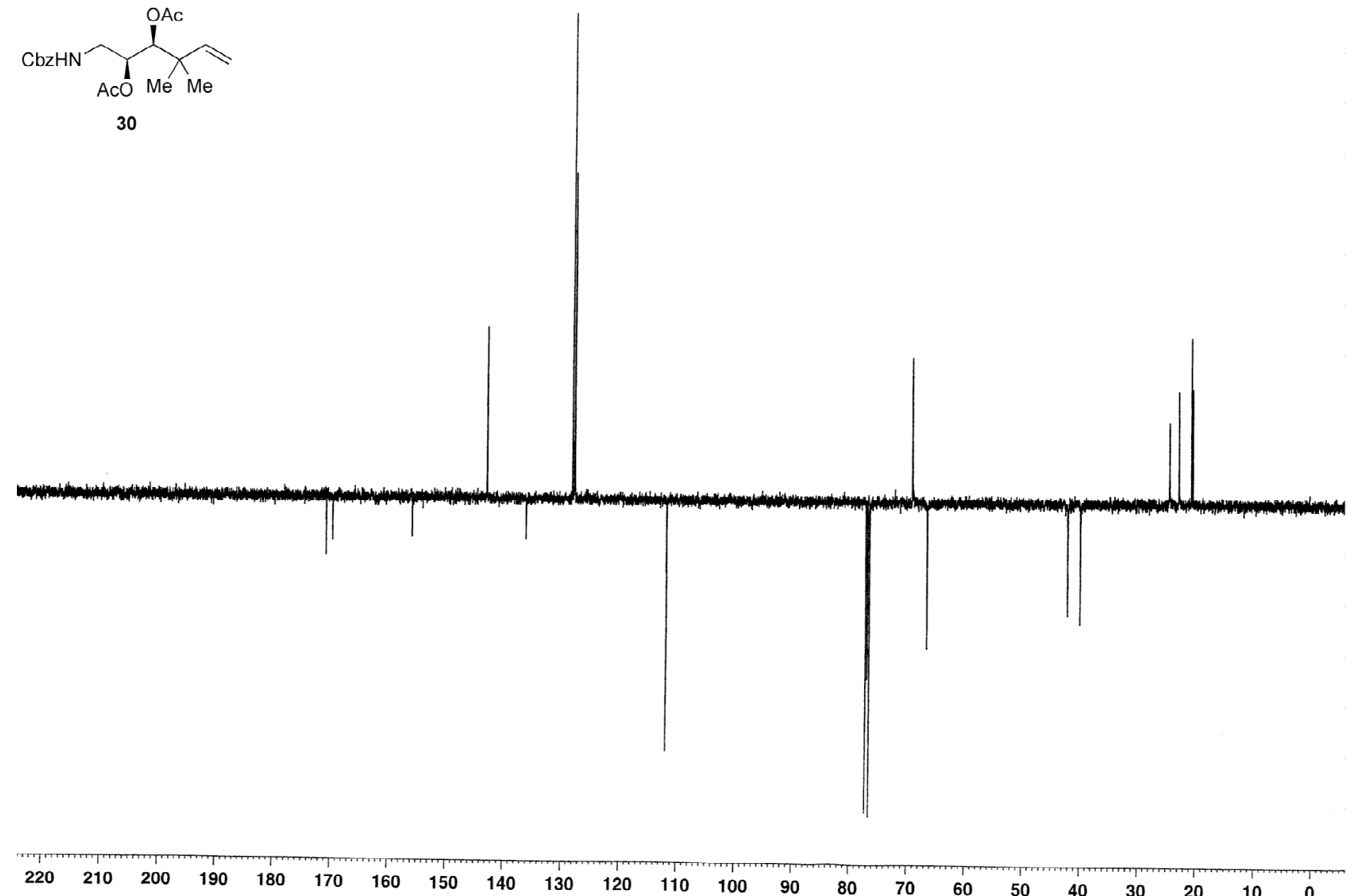


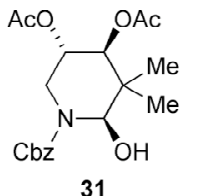

31
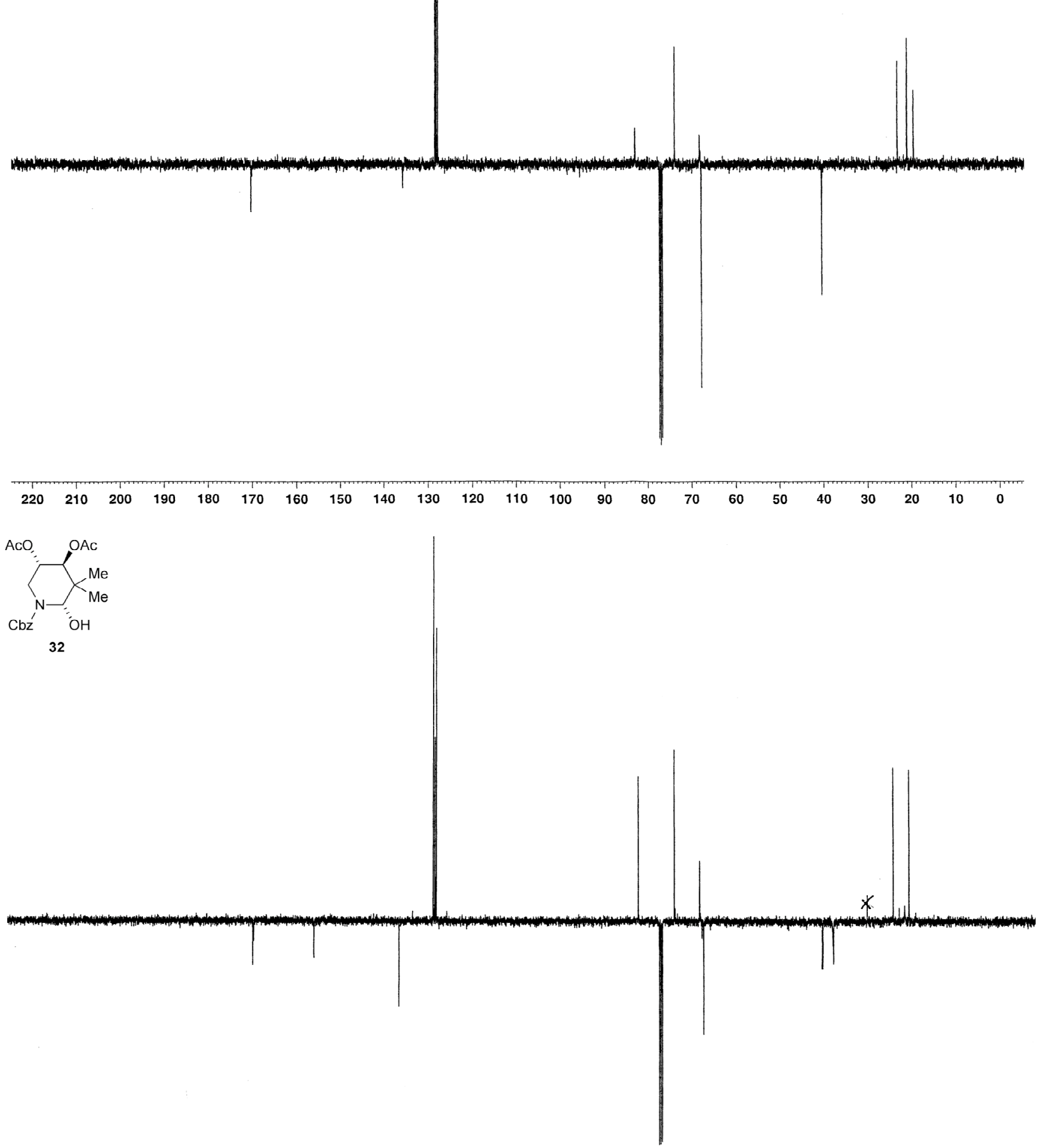

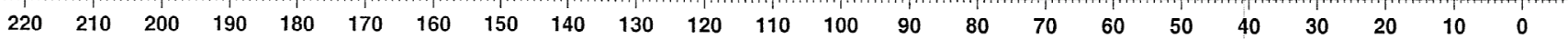



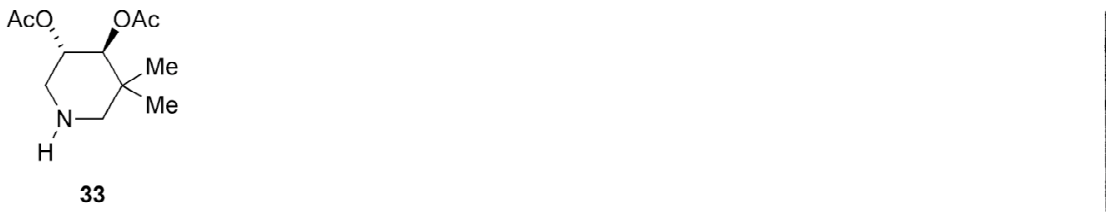

. 